Original Research Article

\title{
A questionnaire based study on the knowledge, attitude and the practices of pharmacovigilance among the postgraduate students at a tertiary care hospital in south India
}

\author{
Chiranjeevi Uday Kumar*, G. Harijagannadha Rao, G. Vasavi
}

Department of Pharmacology, ASRAMS, Eluru, Andhra

Pradesh, India

Received: 15 February 2019

Accepted: 19 February 2019

*Correspondence to:

Dr. Chiranjeevi Uday Kumar,

Email:doc.cuk@gmail.com

Copyright: (c) the author(s), publisher and licensee Medip Academy. This is an openaccess article distributed under the terms of the Creative Commons Attribution NonCommercial License, which permits unrestricted noncommercial use, distribution, and reproduction in any medium, provided the original work is properly cited.

\begin{abstract}
Background: Adverse drug reactions (ADRs) are common cause of morbidity in the practice of medicine. Pharmacovigilance is the science of detection, assessment and understanding and prevention of adverse effects or any drug related problems. Post graduates are perhaps the first to notice ADRs in outpatient/inpatient setup as they spend most of the time bedside. Thus, this study was conducted to assess the knowledge, attitude and practices (KAP) of postgraduates about Pharmacovigilance.

Methods: A prevalidated and pretested questionnaire with 20 questions related to KAP of pharmacovigilance is administered to postgraduate students after obtaining their consent. All the completed and returned questionnaires were analysed for results using appropriate statistics.

Results: 180 pretested questionnaires were distributed among postgraduates out of which, 122 were returned from postgraduates of all major medical and surgical allied departments. $90.2 \%$ defined pharmacovigilance correctly, $83.6 \%$ thought reporting ADRs is a professional obligation, while only $65.6 \%$ knew regarding the existence of national pharmacovigilance program. $58.4 \%$ have experienced ADRs, of which only $24.6 \%$ reported ADR to pharmacovigilance centre. Major reasons for under reporting are lack of time to report and difficulty to decide whether ADR has occurred or not.

Conclusions: In this study, the knowledge and attitude related to Pharmacovigilance is good amongst postgraduates, but practical implementation in reporting of ADRs is poor. Sensitization programs on pharmacovigilance practice in tertiary care hospitals and regular review meetings to ensure ADR reporting to pharmacovigilance centre will strengthen the health care setup.
\end{abstract}

Keywords: Adverse drug reaction, Attitude, Knowledge, Pharmacovigilance, Postgraduates, Practice

\section{INTRODUCTION}

Adverse drug reactions (ADRs) are one of the leading causes of morbidity and represent a substantial economic burden on healthcare resources. ${ }^{1}$ It has been reported that $2.4-6.5 \%$ of the total admissions in the hospitals are due to the adverse reactions, many of which are preventable. ${ }^{2}$ The incidence of serious ADRs is $6.7 \%$ in India. ${ }^{3}$ It is estimated that only $6-10 \%$ of all ADRs are reported. ${ }^{4}$ In India, all healthcare professionals including doctors, nurses, and pharmacists can report an ADR by filling an ADR form of the Central Drugs Standard Control Organization. ${ }^{5}$ It is important for healthcare professionals to know how to report and where to report an ADR. The active participation of healthcare professionals in the Pharmacovigilance program can improve the ADR reporting. ${ }^{6}$

This study was undertaken to assess the knowledge, attitude and practice of Pharmacovigilance of post graduate students at Alluri Sitarama Raju academy of Medical Sciences, Eluru a tertiary care hospital in South India. The major reason for choosing post graduates is that they form the vital link between all stakeholders of patient 
care allied services in hospital like undergraduate students, nursing department and faculty of teaching hospital.

\section{METHODS}

The present study was done at Alluri Sitarama Raju Academy of Medical Sciences. The study was approved by institutional ethics committee. The study was a cross sectional questionnaire based study. The study participants are post graduate students from all clinical departments in the hospital. Prior written informed consent was obtained from all the participants after explaining them about the study and questionnaire. KAP (Knowledge, attitude and practice) Questionnaire was designed to assess the knowledge about pharmacovigilance, attitude towards Pharmacovigilance and their practice on ADR reporting.

There were a total of 20 questions (seven related to knowledge, four related to attitude and eight related to practice). One question was to know the cause for under reporting. The questionnaire was designed based upon earlier studies for assessing KAP of ADR reporting. ${ }^{5-12}$ The KAP questionnaire was validated and pretested to confirm appropriateness and identify whether questionnaire can be self-administered by the doctors. One day time was given to complete and return the questionnaire.

\section{Study criteria}

\section{Inclusion criteria}

Participants who are willing to answer all the questions in questionnaire.

\section{Exclusion criteria}

Incomplete questionnaires were excluded from study.

\section{Statistical analysis}

Statistical analysis was performed using the tabulated data from completed and returned questionnaires. Data were presented either as mean \pm standard deviation (SD) or as percentage and percentages or proportions. All statistical analysis was performed using the Graph Pad PRISM software (version 4, USA).

\section{RESULTS}

In this study a total of 122 post graduates from all 3 years of postgraduation courses from clinical departments were assessed with KAP questionnaire about pharmacovigilance, of which $55.7 \%(n=68)$ were males and $54(n=54)$ were females. The mean average age of the respondents was $30.46 \pm 7.53$ years. Postgraduates from first year were $32.8 \%(n=40)$, second year were $31.1 \%$ $(n=38)$ and third year were $36.1 \% \quad(n=44)$. The demographic details of postgraduates are presented in Table 1 .
Table 1: Demographic details of the post graduate students $(\mathrm{N}=122)$.

\begin{tabular}{|lll|}
\hline \multicolumn{2}{|c|}{$\mathbf{N = 1 2 2}$} & Frequency $(\%)$ \\
\hline Gender & & \\
\hline Male & 68 & 55.7 \\
\hline Female & 54 & 44.3 \\
\hline Mean age (in years) & $30.46 \pm 7.53$ \\
\hline \multicolumn{2}{l}{ Post graduates } \\
\hline $1^{\text {st }}$ year & 40 & 32.8 \\
\hline $2^{\text {nd }}$ year & 38 & 31.1 \\
\hline $3^{\text {rd }}$ year & 44 & 36.1 \\
\hline
\end{tabular}

A total of 122 postgraduate students from 8 clinical departments of which $17 \%$ from general medicine, $16 \%$ from general surgery, $20 \%$ from obstetrics and gynaecology, $8 \%$ from dermatology, $8 \%$ from pulmonology, $15 \%$ from paediatrics, $8 \%$ from orthopaedics and $8 \%$ from psychiatry were assessed in the study for KAP about pharmacovigilance as shown Figure 1.

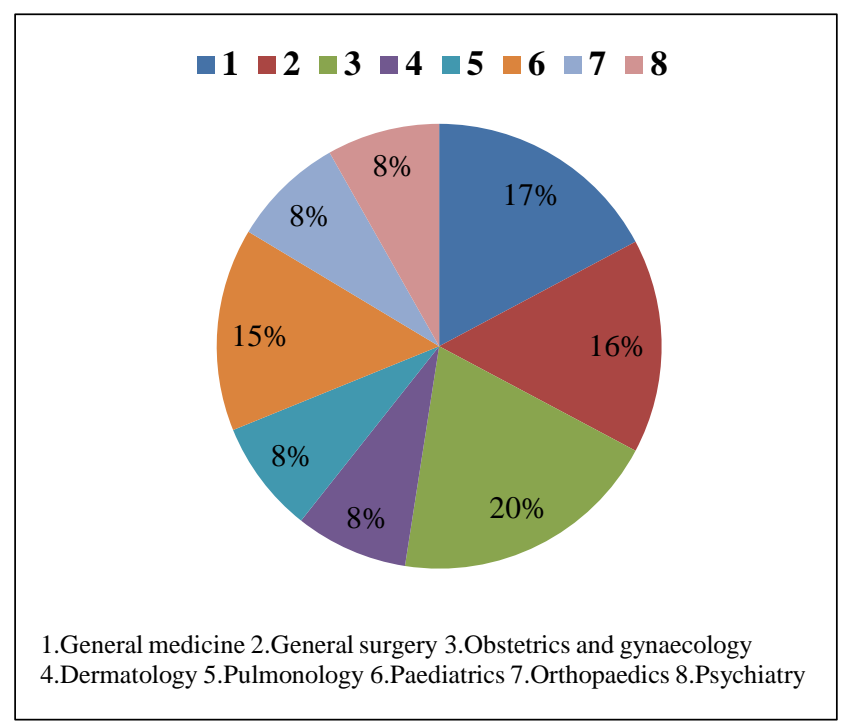

Figure 1: Department wise distribution (\%).

\section{Response rate}

One hundred and eighty questionnaires were distributed among the post graduates and 122 responded by returning completed questionnaires (response rate $67.78 \%$ ).

\section{Knowledge domain}

In the questions based on knowledge, $90.2 \%$ post graduates knew definition of Pharmacovigilance. About $88.5 \%$ considered most important purpose of Pharmacovigilance is to assess safety of drug. $83.6 \%$ felt ADR reporting as a professional obligation, $75.4 \%$ answered correctly health care professional responsible for ADR reporting and $65.6 \%$ were aware regarding the existence of a National Pharmacovigilance Programme in India. 
While only $57.4 \%$ know CDSCO as regulatory body responsible for monitoring ADRs and $44.3 \%$ gave correct response for international monitoring centre for ADR reporting as Uppsala Monitoring Center, Sweden (Table 2).

Table 2: Knowledge based questions and responses.

\begin{tabular}{|lll|}
\hline Knowledge based questions & Correct & Incorrect \\
\hline Define Pharmacovigilance & 90.2 & 9.8 \\
\hline The most important purpose of Pharmacovigilance is & 88.5 & 11.5 \\
\hline Do you think ADR reporting is professional obligation for you? & 83.6 & 16.4 \\
\hline The healthcare professionals responsible for reporting ADRs in a hospital is/are & 75.4 & 24.6 \\
\hline Do you know regarding the existence of a National Pharmacovigilance Programme in India? & 65.6 & 34.4 \\
\hline In India which regulatory body is responsible for monitoring ADRs? & 57.4 & 42.6 \\
\hline Where the international centre for adverse drug reaction monitoring is located? & 44.3 & 55.7 \\
\hline
\end{tabular}

\section{Attitude domain}

Around $94.3 \%$ postgraduates think it's necessary to report an ADR and $90.2 \%$ feel Pharmacovigilance should be taught in detail to health care professionals. About 50.8\% have read an article on prevention of ADRs and around $73.8 \%$ opined positively about establishing adverse drug reaction monitoring centre in every hospital (Table 3 ).

Table 3: Attitude based questions and responses.

\begin{tabular}{|lll|}
\hline Attitude based questions & Correct & Incorrect \\
\hline Do you think reporting of adverse drug reaction is necessary? & 94.3 & 5.7 \\
\hline Do you think Pharmacovigilance should be taught in detail to healthcare professionals? & 90.2 & 9.8 \\
\hline Have you anytime read any article on prevention of adverse drug reactions? & 50.8 & 49.2 \\
\hline $\begin{array}{l}\text { What is your opinion about establishing adverse drug reaction monitoring centre in every } \\
\text { hospital? }\end{array}$ & 73.8 & 26.2 \\
\hline
\end{tabular}

\section{Practice domain}

$58.4 \%$ post graduates have experienced ADRs in their patients, from which only $24.6 \%$ have ever reported ADR to Pharmacovigilance centre. Only $49.2 \%$ have ever seen the ADR reporting form. $60.7 \%$ postgraduates knew regarding Pharmacovigilance committee in their institute. About $55.7 \%$ had ever been trained on reporting ADRs. Around $23 \%$ postgraduates answered correctly that serious adverse event should be reported to the regulatory authority within 14 calendar days. $36.1 \%$ were aware that rare ADRs can be identified during phase 4 clinical trial and $55.3 \%$ acknowledged spontaneous reporting system as a method to monitor ADRs of new drugs in market.

\section{Factors influencing under-reporting}

The most common factor discouraging postgraduates from reporting $\mathrm{ADRs}$ is lack of time to report $\mathrm{ADR}$ (54.1\%), followed by $21.3 \%$ postgraduates who opined that it's difficult to decide whether ADR has occurred or not. $15.6 \%$ felt that a single unreported case may not affect
ADR database, whereas only $9 \%$ expected remuneration for reporting ADRs.

\section{DISCUSSION}

This study was undertaken to assess the KAP of Pharmacovigilance of postgraduate students at our hospital. It is a collective responsibility of all health care professionals in ADR reporting, however we have conducted this study only in postgraduates from all clinical departments. Postgraduate's students coordinate across nursing staff, senior staff and other allied hospital services like pharmacists in the delivery of health care. They are more actively and responsibly involved in patient care services and often the first ones to either witness or get reported about the ADRs from nursing staff. Further, considering their awareness about Pharmacovigilance in their graduation, we conducted this study amongst postgraduate students of all years from all departments.

A modest response rate of around 67.78 is seen in our study, which is comparable to other similar studies. ${ }^{12-14}$ Post graduates from all medical allied (56.6\%) and 
surgical allied departments $(43.4 \%)$ participated in the study.

In our study, participants awareness regarding knowledge related questions is better compared to other studies which were done in health care professionals. ${ }^{11-13}$ For the questions relating to attitude about Pharmacovigilance, results were comparable to other studies done in centres in south India. ${ }^{13-15}$ The reasons for good knowledge and attitude towards Pharmacovigilance can be attributed to the sensitization about ADRs and pharmacology training in undergraduate course. Further seminars and conferences attended by postgraduates and emphasis of importance of ADR reporting under Pharmacovigilance Program of India help strengthen their understanding and knowledge about pharmacovigilance.

In this study, the practice related duties of Pharmacovigilance amongst postgraduates as assessed by questions like the reporting of the ADRs, training on reporting, use of suspected adverse drug reaction reporting form by CDSCO (Central drug standard control organization and timelines for reporting were low and similar to other Indian studies. ${ }^{6,10,15}$ Translation of knowledge and attitude of pharmacovigilance to practice is a major concern as it adversely influences the health care system. The reasons for underreporting in our study could be attributed to busy academic schedules and lack of time for postgraduates followed by difficulty to decide the occurence and causality of ADR. This study emphasizes the need to fill the gaps existing in knowledge and attitude to practice by various measures like CMEs, PVPI awareness programs, regular meetings at tertiary care level to assess ADR reporting and monitoring by health care professionals.

\section{CONCLUSION}

In this study, knowledge and attitude aspects of Pharmacovigilance of postgraduates are reasonably good, attributed to the improving awareness about ADRs. A huge gap was observed between the translation of knowledge and attitude to the implementation and practice of reporting ADRs as a routine practice in hospitals. Guidelines and strict protocols are the need of the hour to improve underreporting of ADRs by conducting awareness and hands on training programs regularly for all health care professionals to encourage ADR reporting practices. Monthly review meetings by heads of the departments and hospital superintendents about the quantity and quality of ADR reporting conforming to standard eporting norms would help build a robust Pharmacovigilance centre in tertiary care hospitals.

\section{ACKNOWLEDGEMENTS}

Authors would like to thank study participants for taking part in the study voluntarily and thank all the departments involved in the study.
Funding: No funding sources

Conflict of interest: None declared

Ethical approval: The study was approved by the Institutional Ethics

(IEC/ASR/APPROVAL/012/2018)

\section{REFERENCES}

1. Kohn LT, Corrigan JM, Donaldson MS. To err is Human: Building a Safer Health System. Institute of Medicine: Washington DC; 2000.

2. Carrasco-Garrido P, de Andrés LA, Barrera VH, Ángel de Miguel G, Jiménez-García R. Trends of adverse drug reactions related-hospitalizations in Spain (2001-2006). BMC Heal Serv Res. 2010; 10:28.

3. Desai CK, Iyer G, Panchal J, Shah S, Dikshit RK. An evaluation of knowledge, attitude, and practice of adverse drug reaction reporting among prescribers at a tertiary care hospital. Perspec Clin Res. 2011;2(4):129-36.

4. Oshikoya KA, Awobusuyi JO. Perceptions of Doctors to Adverse Drug Reaction Reporting in a Teaching Hospital in Lagos, Nigeria. BMC Clin Pharmacol. 2009;9:15.

5. Upadhyaya P, Seth V, Moghe VV, Sharma M, Ahmed M. Knowledge of adverse drug reaction reporting in first year postgraduate doctors in a medical college. Ther Clin Risk Manage. 2012;8:307-12.

6. Remesh A. Identifying the reasons for under reporting of ADR: A cross sectional survey. Res J Pharm Biol Chem Sci. 2012;3:1379-86.

7. Khan SA, Goyal C, Chandel N, Rafi M. Knowledge, attitude and practice of doctors to adverse drug reaction reporting in a teaching hospital in India: An observational study. J Nat Sci Biol Med. 2013;4:1916.

8. Hardeep, Bajaj JK, Kumar R. A survey on the knowledge, attitude and the practice of pharmacovigilance among the health care professionals in a teaching hospital in northern India. J Clin Diagn Res. 2013;7:97-9.

9. Gupta P, Udupa A. Adverse drug reaction reporting and pharmacovigilance: Knowledge, attitudes and perceptions among the resident doctors. J Pharm Sci Res. 2011;3:1064-9.

10. Desai CK, Iyer G, Panchal J, Shah S, Dikshit RK. An evaluation of knowledge, attitude, and practice of adverse drug reaction reporting among prescribers at a tertiary care hospital. Perspect Clin Res. 2011;2:12936.

11. Rajesh R, Vidyasagar S, Varma DM. An educational intervention to assess knowledge attitude practice of pharmacovigilance among health care professionals in an Indian tertiary care teaching hospital. Int J Pharm Tech Res. 2011;3:678-92.

12. Pimpalkhute SA, Jaiswal KM, Sontakke SD, Bajait CS, Gaikwad A. Evaluation of awareness about pharmacovigilance and adverse drug reaction monitoring in resident doctors of a tertiary care teaching hospital. Indian J Med Sci. 2012;66:55-61. 
13. Gupta SK, Nayak RP, Shivaranjani R, Vidyarthi SK A questionnaire study on the knowledge, attitude, and the practice of pharmacovigilance among the healthcare professionals in a teaching hospital in South India. Perspect Clin Res. 2015;6(1):45-52.

14. Hema NG, Bhuvana KB. Pharmacovigilance: the extent of awareness among the final year students, interns and postgraduates in a government teaching hospital Sangeetha. J Clin Diag Res. 2012;6(7):124853.

15. Muraraiah S, Rajarathna K, Sreedhar D, Basavalingu $\mathrm{D}$, Jayanthi CR. A questionnaire study to assess the knowledge, attitude and practice of Pharmacovigilance in a paediatric tertiary care centre. J Chem Pharm Res. 2011;3:416-22.

Cite this article as: Kumar CU, Rao GH, Vasavi G. A questionnaire based study on the knowledge, attitude and the practices of pharmacovigilance among the postgraduate students at a tertiary care hospital in south India. Int J Basic Clin Pharmacol 2019;8:457-61. 